\title{
Percepções dos profissionais de saúde acerca dos fatores biopsicossocioculturais relacionados com o aleitamento materno
}

\author{
Perceptions of Health professionals regarding biopsychosociocultural \\ factors related to breastfeeding
}

Janaine Fragnan Peres', Ariana Rodrigues da Silva Carvalho', Cláudia Silveira Viera', Marialda

Moreira Christoffel'2, Beatriz Rosana Gonçalves de Oliveira Toso'

DOI: 10.1590/0103-1104202112811

RESUMO O aleitamento materno é uma prática social importante, no entanto, sua taxa no Brasil, aproximadamente $40 \%$, está aquém do preconizado pela Organização Mundial da Saúde. Assim, o objetivo do estudo foi compreender as percepções dos profissionais de saúde acerca dos fatores biopsicossocioculturais relacionados com o aleitamento materno. Estudo qualitativo, descritivo e exploratório, realizado por meio de entrevistas semiestruturadas com 28 profissionais de saúde de unidades de saúde da família em município do estado do Paraná. A análise de dados foi temática, os quais foram discutidos à luz do referencial do Modelo Teórico de Promoção da Saúde de Pender. Percebeu-se que o aleitamento materno misto é a prática mais adotada até os 6 meses de vida do recém-nascido e que o trabalho materno atua como a principal barreira que impede a prática do aleitamento materno exclusivo. Aspectos de ordem biológica, cultural e de intervenção profissional também surgiram. Contudo, diversos fatores biopsicossocioculturais que interferem na amamentação exclusiva não foram pontuados como causa do não aleitamento materno exclusivo e desmame precoce. Demonstra-se a importância de profissionais de saúde da atenção primária qualificados e preparados para apoiar a mulher e sua família no processo de amamentação.

PALAVRAS-CHAVE Aleitamento materno. Profissionais de saúde. Desmame precoce.

1 Universidade Estadual do Oeste do Paraná (Unioeste) - Cascavel (PR), Brasil.

janainefp@hotmail.com

2 Universidade Federal do Rio de Janeiro (UFRJ) - Rio de Janeiro (RJ), Brasil.

\begin{abstract}
Breastfeeding is an important social practice, however, its rate in Brazil, approximately $40 \%$, is lower than that recommended by the World Health Organization. Thus, the objective of the study was to understand the perceptions of health professionals about biopsychosociocultural factors related to breastfeeding. Qualitative, descriptive and exploratory study conducted through semi-structured interviews, with 28 health professionals from family health units, in a city in the state of Paraná. Data analysis was thematic and discussed following the Pender Health Promotion Theoretical Model. It was noticed that mixed breastfeeding is the most adopted practice up to six months of life of the newborn, and that maternal work is the main barrier for practicing exclusive breastfeeding. Aspects of biological, cultural, and professional intervention also emerged. However, several biopsychosociocultural factors that interfere with exclusive breastfeeding were not pointed as the cause of non-exclusive breastfeeding and early weaning. The importance of qualified primary health care professionals prepared to support women and their families in the breastfeeding process is demonstrated.
\end{abstract}

KEYWORDS Breast feeding. Health personnel. Weaning. 


\section{Introdução}

A cada dia, novos estudos científicos indicam o leite materno como o alimento primordial para os bebês, sendo incomparável, sustentável e gratuito; que não apenas sacia a fome, mas também supre suas necessidades nutricionais, hormonais e imunológicas $\mathbf{1}$.

Entre as inúmeras vantagens do Aleitamento Materno (AM), autores demonstram que crianças que recebem o Leite Materno (LM) por tempo prolongado apresentam menores índices de morbidade infantil por diarreia, infecções respiratórias e otite média, menores taxas de mortalidade por causas como a enterocolite necrotizante e a síndrome da morte súbita na infância, maior quociente de inteligência e menos má oclusão dentária; além de evidências já demonstrarem que essa prática pode proteger contra sobrepeso e diabetes no decorrer da vida. Para a mãe, esse ato pode prevenir o câncer de mama, aumentar o intervalo interpartal, reduzir o risco de diabetes tipo 2 e câncer de ovário² .

Para um país, o LM também promove incrementos de ordem econômica, seja por meio do aumento do quociente de inteligência, seja pela redução nos custos com assistência à saúde e/ou por possuir sustentabilidade ambiental e não causar poluição, desperdício ou uso de embalagens desnecessárias ${ }^{3}$.

A Organização Mundial da Saúde (OMS) e o Fundo das Nações Unidas para a Infância (Unicef) recomendam o Aleitamento Materno Exclusivo (AME) nos primeiros 6 meses de vida, ou seja, que o bebê só receba LM, sem outro alimento ou bebida, e que o início da alimentação complementar adequada e segura se dê a partir de então, mantendo a amamentação até os 2 anos de idade ou mais 4 . Contudo, apesar de reconhecidamente benéfico, as taxas de AM no mundo ainda se encontram aquém do preconizado pela OMS. Por exemplo, em média, aproximadamente $44 \%$ das crianças com menos de 6 meses são amamentadas exclusivamente com LM ${ }^{5}$.

No Brasil, estudo realizado sobre a tendência de indicadores do AM nas últimas três décadas apontou que a prevalência do AME entre os menores de 6 meses teve ganhos significativos até o ano de 2006, indo de 2,9\% em 1986 para $37,1 \%$ no referido ano, porém, com estabilização em 2013, com 36,6\%. Por outro lado, a amamentação continuada até o segundo ano manteve-se estável entre 1986 e 2006 (24,5\% e $24,7 \%$ respectivamente), sendo o único indicador com aumento da prevalência nesse período, elevando-se para 31,8\% em $2013^{6}$.

Desde a década de 1980, diversos foram os esforços empreendidos no País em prol da amamentação, respaldados por políticas públicas baseadas em estratégias de apoio, proteção e promoção do AM como forma de combate à morbimortalidade infantil 7 .

No entanto, existem fatores biológicos, sociais, econômicos, culturais e psicológicos que influenciam nesse processo e que vão além de uma política específica ${ }^{7}$. Há que se considerar o contexto biopsicossociocultural no qual a mulher está inserida, visto que muitos são os determinantes que exercem influências na iniciação e na manutenção do AM e que, por isso, devem ser criteriosamente avaliados ${ }^{8}$.

Assim, para promover o AME, torna-se imprescindível ampliar a visão sobre a promoção da saúde, admitir que o processo saúde-doença é decorrente de múltiplos aspectos e que, para promover a saúde, não devemos considerar apenas a singularidade dos sujeitos e coletividades, mas reconhecer que o tema está condicionado e determinado pelos contextos social, econômico, político e cultural, o que não se assegura somente pelo setor saúde e demanda articulação e cooperação intra e intersetorial, com ampla participação e controle social ${ }^{9}$.

Todavia, os profissionais de saúde, de forma recorrente, têm considerado a amamentação como ato puramente instintivo e biológico, desconsiderando o processo biopsicossociocultural, dinâmico e relacional que envolve essa prática ${ }^{10}$. Diante disso, o objetivo do estudo foi compreender as percepções dos profissionais de saúde acerca dos fatores biopsicossocioculturais relacionados com o AM. 


\section{Material e métodos}

Trata-se de um estudo descritivo e exploratório, com abordagem qualitativa que estudou as crenças, as representações, as percepções e as interpretações dos profissionais de saúde acerca do $\mathrm{AM}^{\mathbf{1}}$. $\mathrm{O}$ estudo integra um projeto multicêntrico, denominado 'Aleitamento materno exclusivo: determinantes socioculturais no Brasil', sob coordenação da Escola de Enfermagem Anna Nery, do Rio de Janeiro.

Esta pesquisa foi realizada com 28 profissionais de saúde (médicos, enfermeiros, técnicos de enfermagem e agentes comunitários de saúde) que trabalhavam em Unidades urbanas de Estratégia Saúde da Família (USF) em município de médio porte na região Oeste do Paraná.

As USF foram selecionadas por amostragem aleatória simples. Para tanto, foi utilizado o aplicativo de celular Random Number Generator para selecionar as USF de acordo com o Distrito Sanitário, totalizando sete USF para a coleta de dados com os profissionais de saúde.

A distribuição por categoria profissional se deu de forma intencional, ou seja, 25\% eram médicos; $25 \%$, enfermeiros; $25 \%$, Técnicos em Enfermagem; e 25\%, Agentes Comunitários de Saúde (ACS), uma vez que a decisão foi de entrevistar pelo menos um profissional de cada categoria em uma mesma equipe da USF. Os dados foram coletados entre setembro e novembro de 2018. A princípio, foi realizado contato telefônico com as coordenadoras das unidades com a finalidade de realizar o convite de participação no estudo e, consequentemente, definir as datas e horários para sua realização. Nos dias em que ocorreram os encontros, o pesquisador apresentou a proposta da pesquisa ao participante, informando-o sobre o desenvolvimento e os objetivos a serem alcançados. Visando resguardar a privacidade dos entrevistados e proporcionar segurança para que pudessem expor suas vivências, as entrevistas ocorreram em salas e consultórios da unidade, com porta fechada, somente com o pesquisador e o participante do estudo.

As entrevistas foram realizadas por meio de um roteiro semiestruturado com as principais questões: qual é a forma mais comum das mães alimentarem seus bebês em sua comunidade? Você acredita que as mulheres de sua comunidade enfrentam alguma barreira que as impeça de alimentar ao seio materno de forma exclusiva?

As entrevistas foram gravadas; e, após a realização de cada uma, foi feita a escuta atenta da gravação e, posteriormente, a transcrição para a leitura textual. A finalização da coleta de dados deu-se quando ocorreu a saturação, ou seja, a partir do momento em que as vivências e as respostas dos entrevistados começaram a se repetir.

Os dados obtidos por meio das entrevistas foram submetidos à análise de conteúdo temática, seguindo-se as etapas: pré-análise, exploração do material e tratamento dos resultados obtidos e interpretação. Na pré-análise, organizaram-se os conteúdos em quadros sistematizadores para visualizar, de maneira geral, as entrevistas. Na sequência, realizou-se a exploração do material que possibilitou a construção de categorias que configuram a estrutura do fenômeno estudado. Para finalizar, foram realizados o tratamento e a interpretação dos dados, que foram agrupados em duas categorias temáticas, discutidas à luz do referencial do Modelo Teórico de Promoção da Saúde (MTPS).

O MTPS foi desenvolvido na década de 1980 por Nola J. Pender, professora emérita da Escola de Enfermagem da Universidade de Michigan, Estados Unidos, com a finalidade de identificar os fatores que influenciam comportamentos saudáveis, além de explorar o complexo biopsicossocial que motiva indivíduos para se engajarem em comportamentos produtores de saúde ${ }^{\mathbf{1 2}}$.

O MTPS repousa sobre a concepção de promoção da saúde, definida como aquelas atividades destinadas a aumentar o nível de bem-estar e autorrealização de indivíduos, famílias, comunidades e sociedade e, portanto, é essencialmente um modelo de enfermagem. Sendo assim, esse modelo pode ser usado para 
implementar e avaliar as ações de promoção da saúde e os comportamentos que levam à promoção da saúde, por meio do estudo da inter-relação de três pontos principais: 1) as características e experiências individuais; 2) os sentimentos e conhecimentos sobre o comportamento que se quer alcançar; e 3) o comportamento de promoção da saúde desejável12.

Assim, os profissionais de saúde devem reconhecer os comportamentos que são promotores do AME e identificar os fatores que atuam nessa prática, com a finalidade de minimizar ou impedir as barreiras que dificultam a adoção da prática do AME.

A pesquisa seguiu os preceitos éticos da Resolução no 466/2012, do Conselho Nacional de Saúde, e foi aprovada por Comitê de Ética em Pesquisa da Universidade Federal do Rio de Janeiro (UFRJ) sob parecer número 2.507.525 e CAAE número: 80711517.8.1001.5238. Os participantes assinaram o Termo de Consentimento Livre e Esclarecido. A fim de assegurar o sigilo de sua identidade, os participantes foram identificados por códigos, sendo a letra M para os médicos, a letra $\mathrm{E}$ para os enfermeiros, as letras TE para técnicos em enfermagem, e as letras ACS para os agentes comunitários de saúde. As entrevistas em cada grupo foram numeradas conforme a ordem de sua realização. Por exemplo: M1, M2, E1, E2, TE1, TE2, ACS1, ACS2 e assim sucessivamente.

\section{Resultados}

Na caracterização dos entrevistados, houve predomínio do sexo feminino ( $82 \%$ ), e a faixa etária variou de 24 a 54 anos, sendo que a idade entre 30 e 39 anos predominou (43\%). Entre os 14 profissionais com graduação universitária, 10 têm especialização. O tempo de formação na profissão variou de 7 meses a 29 anos, predominando o período de formação entre 5 e 10 anos (28\%). O tempo de trabalho com amamentação predominante foi de 5 a $10 \operatorname{anos}(29 \%)$, período que coincide com o tempo de formação.
Quanto à formação para o $\mathrm{AM}$, a maioria dos médicos (86\%) afirmou não ter realizado nenhum curso e/ou qualificação nessa temática, já a maioria dos técnicos em enfermagem (57\%) recebeu algum tipo de treinamento. Entre os enfermeiros e ACS, todos (100\%) participaram de cursos e/ou capacitações.

$\mathrm{Na}$ análise temática dos dados, produziram-se duas categorias: 'Alimentação do lactente' e 'Barreiras para a alimentação exclusiva ao seio materno'.

\section{Alimentação do lactente}

Os profissionais de saúde entrevistados mencionaram que o LM é o alimento predominante nos primeiros 6 meses de vida da criança. No entanto, afirmam que poucas são as mães que conseguem mantê-lo de forma exclusiva, associando-se ao fato de a mulher não exercer atividade remunerada. "Como a grande parte das mulheres aqui do bairro não trabalham, ou se trabalham pegam uma licença, elas praticam bem a amamentação" (M1).

Diante disso, o AM misto ou parcial é o tipo de alimentação mais frequente nessa faixa etária na visão dos participantes da pesquisa, sendo citado por 16 deles, revelando que "muitas mulheres acabam dando complemento antes dos seis meses" (E6); e "acham mais prático começar o aleitamento artificial” (M6).

Quanto ao tipo de leite utilizado pela mulher juntamente com o LM, observou-se que essa escolha se associa ao nível socioeconômico da mulher e da sua família:

Elas começam a introduzir o leite que elas têm condições, leite de lata, elas compram esses, geralmente indicado pelo médico, e depois vão para o leite de pacote (ACS6); [ou] algumas, que tem nível social mais difícil, às vezes já começam até com leite de vaca e dando direto leite de vaca e param de amamentar cedo (M4).

Um profissional de saúde fez menção ao Programa Leite das Crianças, um programa do estado do Paraná que tem por objetivo auxiliar 
o combate à desnutrição infantil, por meio da distribuição gratuita e diária de um litro de leite às crianças de 6 a 36 meses $^{13}$.

A maioria é fórmula mesmo, mas tem até o programa leite das crianças, que às vezes até está em AME, mas como elas sabem que tem esse programa, elas acabam fazendo o cadastro e pegando e dando, de vez em quando, esse outro tipo de leite, que é leite de vaca de pacote. (E7).

O AM predominante apareceu em alguns discursos, geralmente associado à "influência de pessoas da família, como pais e avós, que acabam a dar chazinhos, sucos, porque é bom para cólica, é bom para isso e aquilo" (ACS4).

Nesse contexto, alguns profissionais de saúde afirmaram que as mães iniciam a alimentação complementar "geralmente, em torno dos quatro, cinco meses elas já introduzem algumas papinhas"(M5).

\section{Barreiras para a alimentação exclusiva ao seio materno}

Entre os aspectos socioculturais que influenciam na amamentação, os profissionais afirmaram que o trabalho materno é a principal barreira que impede a duração do AME até o período mínimo recomendado, visto que, "no trabalho privado, elas têm só quatro meses de licença” (TE6), e a maior parte das mulheres "trabalha na condição de CLT [Consolidação das Leis do Trabalho], daí tem 120 dias de licença maternidade” (M6). Além disso, alguns profissionais destacaram que algumas mulheres "não têm liberação para amamentar, não tem uma creche próxima"(M3) quando retornam ao trabalho e "nem sempre a empresa vai permitir que a mãe saia de lá para vir amamentar o bebe" (TE6).

Emergiram ainda nas entrevistas os aspectos biológicos, que dizem respeito às condições biológicas da mãe ou do recém-nascido e ao manejo da amamentação, alegando que

[...] geralmente com a pega inadequada fazem fissuras, o que também acaba fazendo algumas mães desanimarem e desistirem da amamentação, por causa da dor (M5), [ou] por conta do bico do seio, mamilo invertido, e as vezes pela condição clínica da criança acabam introduzindo o complemento (E3), bico rachado, mastite, ingurgitamento, que faz, às vezes, elas desistirem (E5), também casos de mãe com obesidade, bebê nasceu e a gente tentou até segundo, terceiro mês, e ela preferiu fórmula, é mais fácil (TE3), tem aquelas que passam por estresse e acaba diminuindo o leite e acaba tendo que entrar com industrializado (TE4); [e,] também eu tenho um grande índice de mulheres com depressão pós-parto, às vezes ela não quer fazer o aleitamento (ACS2).

Alguns profissionais apontaram os aspectos culturais como uma barreira que impede o AME até o sexto mês de vida, associando-os a aspectos estéticos, mitos e crenças, visto que algumas "escutam mitos de que o seio cai, que o leite é fraco" (M5, E1, E4, E5, TE7), ou que "tem pouco leite" (E5), "o leite é só água" (ACS5), geralmente atrelados à influência das pessoas do contexto familiar:

[...] porque fica muito com vó, e aí a vó introduz os chazinhos, introduz as sopinhas, introduz as papinhas, muito cedo, porque acha que a criança está com fome, principalmente porque acha que o leite é fraco (E4), [e a crença de achar que o leite] causa gases demais no bebê, que não sustenta (E1).

Outro aspecto que emergiu nessa temática foi relacionado com "prescrição de suplementação por pediatras” (E1), justificando que

\section{[...] a criança está com o desenvolvimento perfeito, às vezes superiores aos percentis recomendados, e mesmo assim eles entram com suplementação e elas falam que ele [médico] achou que o leite estava sendo muito pouco e precisava comple- mentar. (E1).}

Outros relataram que muitos pediatras prescrevem fórmulas infantis antes dos 6 meses de vida da criança: 
Depois que faz o acompanhamento com o pediatra já vem muitas vezes com a fórmula, então essa é uma dificuldade que eu enfrento aqui, os pediatras costumam fazer a prescrição de fórmulas antes do sexto mês. (E3).

\section{Discussão}

Estudo demonstra que, embora os índices de AM no Brasil tenham apresentado ganhos significativos ao longo do tempo, os indicadores estão muito aquém das recomendações quanto a sua duração $0^{6}$. Além disso, estudo transversal para avaliar o consumo de leites entre menores de 1 ano de idade aponta que $55 \%$ das crianças menores de 6 meses recebem LM associado com leite não materno, sendo este a fórmula infantil ou o leite de vaca ${ }^{14}$. Esses dados corroboram a citação dos profissionais de saúde ao AM misto ou parcial como principal fonte de alimentação de crianças até os 6 meses de idade e demonstram que essa forma de alimentação é o comportamento anterior/prévio do MTPS que precisa ser considerado para elaborar as intervenções de saúde e, assim, alcançar o comportamento de saúde desejável, que, nesse caso, é o AME.

O comportamento anterior/prévio do modelo teórico de Nola Pender é definido como os hábitos passados relacionados com a busca da saúde, e está vinculado à concepção de que existem fatores pessoais que interferem diretamente no comportamento e nas ações dos indivíduos para a promoção da saúde ${ }^{\mathbf{2} 2}$.

Nesse contexto, os fatores pessoais, que incluem aspectos biológicos, psicológicos e socioculturais, podem influenciar os resultados da saúde e, por isso, devem se limitar àqueles que são teoricamente relevantes para o comportamento de saúde proposto ${ }^{\mathbf{1 2}}$. Assim, na literatura sobre a amamentação, o uso de chupetas ${ }^{8,15,16}$, mamadeiras e chuquinhas ${ }^{16}$, retorno ao trabalho materno ${ }^{3,17,18}$ ou ao estudo $^{18}$, baixo número de consultas de pré-natal ${ }^{8}$, parto cesariano, menor idade materna, multiparidade ${ }^{16}$, entre outras, são fatores relevantes para a duração da amamentação e, por isso, devem ser considerados quando se deseja alcançar o AME. Todavia, entre essas múltiplas variáveis associadas ao não consumo de AME, os profissionais de saúde entrevistados referiram a questão do trabalho materno, levando a perceber que outros determinantes apontados na literatura como importantes nesse processo não são considerados como causas do não AME.

Quanto aos tipos de leite inseridos na alimentação infantil, estudos demonstram que o consumo de leite de vaca aumenta conforme os meses de idade da criança, comprovando que esse tipo de leite é consumido pelas crianças antes de 1 ano de idade, em especial aquelas pertencentes às famílias de menor nível socioeconômico ${ }^{\mathbf{1 4}, 17}$, de acordo com o mencionado pelos participantes do estudo. Nessa conjuntura, acrescenta-se que o consumo desse tipo de leite antes dos 6 meses da criança pode estar ligado ao fato de a família ser inserida em programa social para recebimento de leite e de outras crianças da família receberem o benefício, e a mãe fazer o uso do leite para todas, independentemente da idade $\mathbf{1 4}^{\mathbf{4}}$, como relatado pelos profissionais dessa pesquisa.

Nessa vertente, verifica-se que os profissionais de saúde reconheceram a renda familiar como um fator sociocultural que pode influenciar na escolha do tipo de leite ofertado à criança. No entanto, torna-se imprescindível que essa variável também seja correlacionada como um fator preditivo no AME, visto que existe associação positiva entre o percentual de conhecimento de puérperas sobre o AM e a renda familiar, demonstrando que puérperas com maior renda familiar apresentaram maior conhecimento sobre o $\mathrm{AM}^{19}$.

Dessa forma, esse é um fator que exerce influências no AME e, embora não seja passível de alteração pelos profissionais de saúde isoladamente, oferece uma base para a personalização das intervenções de saúde ${ }^{\mathbf{1 2}}$. Entretanto, destaca-se que a recomendação é de não introduzir leite de vaca na dieta de crianças menores de 1 ano de idade, por ser 
pobre em ferro e zinco e ser um dos grandes responsáveis pela alta incidência de anemia ferropriva em menores de 2 anos, além de ser um alimento muito alergênico para crianças e seu consumo estar associado ao desenvolvimento de atopia'.

Assim, diante da impossibilidade do AM ou quando esgotadas todas as possibilidades de relactação, deve-se utilizar uma fórmula infantil que satisfaça as necessidades do grupo etário; e, caso existam dificuldades financeiras para sua aquisição, os profissionais de saúde devem orientar as mães, famílias e cuidadores quanto à utilização mais adequada e segura do leite de vaca'?

Quanto à menção à introdução de alimentos complementares na dieta de crianças menores de 6 meses, estudo realizado na região Noroeste de Goiás aponta que é comum o consumo de chás e água no primeiro mês, sendo ainda mais acentuado no quarto mês, acompanhado também de outros leites e sucos. Já no sexto mês, mais da metade das crianças consumiam água, frutas, sucos e comida de $\mathrm{sal}^{20}$. Esses achados corroboram outro estudo realizado em Minas Gerais, no qual as mães das crianças menores de 6 meses relataram ter dado aos seus filhos papa de frutas e suco de frutas, caracterizando a introdução precoce da alimentação complementar ${ }^{16}$.

Segundo o Ministério da Saúde (MS), a introdução de alimentos complementares antes dos 6 meses de idade pode acarretar prejuízos à saúde da criança, pois está associada a episódios de diarreia, doenças respiratórias, risco de desnutrição e menor absorção de ferro e zinco ${ }^{1}$. Adicionalmente, essa prática interfere diretamente na duração do AM e influencia negativamente na duração do AME, sendo um comportamento que precisa ser analisado pelos profissionais de saúde para que ações efetivas sejam realizadas. Nesse âmbito, o MS recomenda, a partir dos 6 meses, a introdução lenta e gradual de outros alimentos, além do LM, visto que, nesse período, a criança já apresenta maturidade fisiológica e neurológica para receber outros alimentos ${ }^{1}$.
Quanto ao trabalho materno atuar como uma barreira para a amamentação exclusiva ao seio materno, estudo evidenciou que as mães trabalhadoras que estavam em licença maternidade apresentaram menor chance de interrupção do AME nos primeiros 4 meses de vida do lactente, demonstrando que o aumento da prevalência do AME em no Brasil está associada à licença maternidade e que sua ampliação poderia beneficiar milhares de mulheres e seus filhos ${ }^{21}$. Em contrapartida, outro estudo aponta que, mesmo tendo um plano para amamentar e conhecimentos sobre os benefícios do AM, o retorno ao trabalho, juntamente com fatores que não favorecem a continuidade da amamentação, causa a interrupção frequente dessa prática ${ }^{22}, 0$ que evidencia a insuficiência dos direitos trabalhistas para o cumprimento da amamentação exclusiva até o sexto mês de vida ${ }^{23}$.

Sendo assim, verifica-se que o ambiente de trabalho pode atuar como uma barreira percebida para a ação, ou seja, um bloqueio real representado por dificuldades e/ou limitações de permanecer na prática do AME, uma vez que, geralmente, quando as mulheres retornam a suas atividades laborais, o seguimento desse comportamento torna-se difícil. Além disso, os fatores psicológicos atrelados ao retorno da mulher ao trabalho podem ser associados a variáveis como autoestima, automotivação e competência pessoal para a continuidade desse comportamento ${ }^{12}$.

No que concerne aos aspectos biológicos, estudo realizado com 276 binômios mãe-lactente atendidos em maternidades no norte de Minas Gerais nas primeiras 18-48 horas pós-parto evidenciou uma elevada prevalência de condições indicativas de dificuldades iniciais com a técnica da amamentação, destacando-se a pega inadequada $(25,0 \%)$ e os problemas com a mama $(28,3 \%)$, englobando neste último, principalmente, a presença de fissuras e mamilo plano ${ }^{24}$. Outro estudo realizado sobre os fatores que interferem na amamentação exclusiva, constatou que os problemas mamários, como dor e desconforto, estão entre os principais que levam ao desmame precoce, 
já o tipo de mamilo também tem influência nessa prática, mas não a impede ${ }^{25}$.

Nesse contexto, o MS afirma que, apesar da sucção do recém-nascido ser um ato reflexo, ele precisa aprender a retirar o leite do peito de forma eficiente; e, muitas vezes, a técnica da amamentação, incluindo a posição e a pega, precisa ser ensinada e observada pelos profissionais de saúde na tentativa de evitar complicações relacionadas com a amamentação e que podem levar ao desmame precoce ${ }^{1}$. Assim, quando os profissionais de saúde desta pesquisa declaram que os problemas relacionados com os aspectos biológicos, principalmente aqueles envolvendo problemas mamários, atuam como uma barreira percebida para o AME, deve-se refletir sobre como está ocorrendo a orientação e o acompanhamento sobre amamentação no pré-natal, no pós-parto hospitalar e domiciliar e o manejo clínico adequado desses casos no sentido de minimizar essas complicações para que não impeçam o AME, pois, de acordo com o MTPS, esses fatores biológicos são variáveis que precisam ser reconhecidas pelos profissionais de saúde porque são passíveis de mudança ${ }^{12}$.

Quanto aos aspectos culturais, os mitos e as crenças que envolvem o AM, como o leite fraco, pouco leite, flacidez das mamas e uso precoce de água e chás, sugerem, em sua maioria, a não efetividade do LM e, por isso, são influenciadores negativos da manutenção da amamentação - e a confiabilidade que a mulher dá a esses conceitos exibe o quanto a intervenção da cultura e a herança dos comportamentos familiares são mentores da conduta materna ${ }^{26}$.

A cultura familiar referida neste estudo também é apontada em uma revisão integrativa sobre os fatores que interferem na amamentação exclusiva, a qual verificou que as pessoas que convivem com a nutriz estão diretamente ligadas à manutenção da amamentação, visto que são dotadas de experiências, crenças e valores culturais repassados de geração que irão interferir fortemente nas práticas maternas, na sua segurança para a amamentação e em seus medos e dúvidas ${ }^{25}$.
Ainda nessa temática, questões culturais envolvendo mitos e crenças relacionados com a amamentação, como as expressões 'leite fraco', 'pouco leite' ou 'o bebê não quis pegar o peito', evidenciam a insegurança da mãe ante o processo da amamentação e podem ser determinantes na introdução precoce de outros alimentos ${ }^{27}$. $O$ que foi também verificado em outra pesquisa, na qual se notou que as mães inseriam outros alimentos na dieta da criança, como farináceos e leite industrializado, com o AM, pela crença de que produziam pouco leite, que seu leite era 'fraco', que a criança não pegava o 'bico' do seio e que desconheciam dos benefícios do AME ${ }^{28}$.

Essas influências interpessoais, que são os conhecimentos, atitudes ou crenças de familiares, cônjuges, cuidadores de saúde, ou normas e modelos sociais, podem interferir positivamente ou negativamente na prática do AME ${ }^{12}$. Sendo assim, os profissionais de saúde que prestam cuidados diretos à mulher, relacionados com a prática correta da amamentação, devem valorizar os conhecimentos e as crenças preconcebidos por ela, uma vez que as orientações profissionais, muitas vezes, diferem do saber popular e podem gerar dúvidas e confusão diante do seu seguimento, causando insegurança na nutriz ${ }^{29}$.

No que se refere à prescrição de fórmulas infantis, estudo com a finalidade de identificar a frequência e a justificativa para seu uso em maternidades constatou que $47,5 \%$ das crianças avaliadas estavam em uso de suplementos, e apenas $6,88 \%$ das prescrições estavam dentro das normas internacionais de recomendação ao uso de fórmulas infantis, como casos de infecções maternas com agentes de alta patogenicidade ou que exijam o uso de medicamentos incompatíveis com a amamentação ${ }^{30}$.

Nesse âmbito, os próprios profissionais de saúde tornam-se barreiras para a prática do AME, pois, conforme apontado pelo MS, a prescrição desses produtos para crianças que não necessitam desses alimentos deve ser considerada inapropriada, visto que tem impacto negativo na promoção da amamentação e na saúde infantil1. 


\section{Considerações finais}

Os profissionais de saúde reconhecem que o AME ainda não é uma realidade no Brasil e que o AM misto é a prática mais adotada até os 6 meses de vida do recém-nascido. Além disso, identificam algumas barreiras como impeditivas na adoção do comportamento de saúde esperado, que, nesse caso, trata-se do AME. Entretanto, existem diversos fatores biopsicossocioculturais que não foram pontuados e/ou que estão sendo preteridos pelos profissionais de saúde como causas do não AME e desmame precoce e que precisam ser identificados, pois representam dificuldades e limitações na adoção de comportamentos saudáveis.

Destaca-se a importância de profissionais de saúde da atenção primária qualificados para apoiar a mulher e sua família no processo de amamentação durante o pré-natal, além de na maternidade e no pós-parto. No entanto, na caracterização dos profissionais, constataram-se problemas com a formação para o tema, já que mais da metade dos técnicos de enfermagem e todos os enfermeiros e ACS realizaram cursos/capacitações em AM, ao passo que a maior parte dos médicos não recebeu nenhum treinamento/qualificação nessa temática (ainda mais porque cabe aos médicos prescrever fórmulas infantis). Diante disso, sendo o conhecimento uma ferramenta importante para atuação dos profissionais de saúde, a falta de capacitações em AM pode se tornar um obstáculo para sua prática.

Para promover o AME, portanto, é necessário identificar, seguindo o MTPS, quais são os fatores biológicos, psicológicos e socioculturais presentes que atuam positivamente ou negativamente na prática do AM, bem como as barreiras e os benefícios que são percebidos para essa ação, conforme explicitado no decorrer das discussões, para auxiliar na implementação de intervenções e estratégias que resultem em mudanças nos comportamentos de saúde e melhoria da qualidade de vida.

Refere-se como uma das limitações do estudo e, portanto, indica-se a necessidade de ouvir também as mulheres em processo de amamentação para entender se a sua percepção está refletida naquela que os profissionais de saúde da atenção primária mencionam, pois a comunicação efetiva entre ambos é mister para o auxiliar no processo de AM.

\section{Colaboradoras}

Peres JF (0000-0003-0681-2459)* e Toso BRGO (0000-0001-7366-077X)* contribuíram igualmente para concepção, planejamento, análise e interpretação dos dados; para elaboração do rascunho e revisão crítica do conteúdo e participação na aprovação da versão final do manuscrito. Carvalho ARS (0000-00022300-5096)* contribuiu para organização da coleta de dados, coorientação da interpretação dos dados, leitura da primeira versão do manuscrito e revisão crítica do conteúdo. Viera CS (0000-0002-0900-4660)* e Christoffel MM (0000-0002-4037-8759)* contribuíram igualmente para revisão crítica do conteúdo e participação na aprovação da versão final do manuscrito. 


\section{Referências}

1. Brasil. Ministério da Saúde, Secretaria de Atenção à Saúde, Departamento de Atenção à Saúde. Saúde da criança: aleitamento materno e alimentação complementar. 2. ed. Brasília, DF: MS; 2015.

2. Victora CG, Bahl R, Barros AJD, et al. Breastfeeding in the 21st century: epidemiology, mechanisms, and lifelong effect. Lancet [internet]. 2016 [acesso em 2019 jan 20]; 387(10017):475-90. Disponível em: http://linkinghub.elsevier.com/retrieve/pii/S0140673615010247.

3. Rollins NC, Bhandari N, Hajeebhoy N, et al. Why invest, and what it will take to improve breastfeeding practices? Lancet [internet]. 2016 [acesso em 2019 jan 20]; 387(10017):491-504. Disponível em: http://scilo.iec. pa.gov.br/pdf/ess/v25nl/Amamentacao2.pdf.

4. Organización Panamericana de la Salud. La alimentación del lactante y del niño pequeño. Capítulo Modelo para libros de texto dirigidos a estudiantes de medicina y otras ciencias de la salud. Washington, D.C.: OPS; 2010.

5. World Health Organization. Infant and young child feeding. Media Cent [internet]. 2020 [acesso em 2019 jan 20]. Disponível em: https://www.who.int/news-room/fact-sheets/detail/infant-and-young-child-feeding.

6. Boccolini CS, Boccolini PDMM, Monteiro FR, et al. Breastfeeding indicators trends in Brazil for three decades. Rev Saude Publica [internet]. 2017 [acesso em 2019 jan 20]; 51(108):108. Disponível em: http:// www.revistas.usp.br/rsp/article/view/140946.

7. Brasil. Ministério da Saúde, Secretaria de Atenção à Saúde, Departamento de Ações Programáticas Estratégicas. Bases para a discussão da Política Nacional de Promoção, Proteção e Apoio ao Aleitamento Materno. Brasília, DF: MS; 2017.

8. Boccolini CS, Carvalho ML, Couto de Oliveira MI. Factors associated with exclusive breastfeeding in the first six months of life in Brazil: A systematic review. Rev Saude Pub. 2015; (49):1-15.
9. Brasil. Ministério da Saúde, Secretaria de Vigilância em Saúde, Secretaria de Atenção à Saúde. Política Nacional de Promoção da Saúde (PNPS). Brasília, DF: MS; 2018.

10. Almeida JM, Araújo S, Luz B, et al. Support of breastfeeding by health professionals: integrative review of the literature. Rev Paul Pediatr (English Ed) [internet]. Associação de Pediatria de São Paulo; 2015 [acesso em 2019 jan 20]; 33(3):355-62. Disponível em: http://dx.doi.org/10.1016/j.rppede.2015.06.016.

11. Minayo MCS. O desafio do conhecimento: pesquisa qualitativa em saúde. 14. ed. São Paulo: Hucitec; 2014.

12. Pender NJ, Murdaugh CL, Parsons M. Health Promotion in Nursing Practice. 6. ed. Upper Saddle River: Pearson; Prentice-Hall; 2011.

13. Secretaria da Agricultura e do Abastecimento do Paraná. Programa Leite da Crianças [internet]. 2019 [acesso em 2019 jan 20]. Disponível em: http://www. leitedascriancas.pr.gov.br/modules/conteudo/conteudo.php?conteudo=1.

14. Saldan PC, Venancio SI, Saldiva SRDM, et al. Milk consumption in infants under one year of age and variables associated with non - maternal milk consumption Consumo de leites em menores de um ano de idade. Rev Paul Pediatr. 2017; 35(4):407-14.

15. Carvalho JLS, Cirino IP, Lima LHO, et al. Conhecimento das mães sobre aleitamento materno exclusivo e alimentação complementar. Saúde em Redes [internet]. 2016 [acesso em 2019 jan 20]; 2(4):38392. Disponível em: http://revista.redeunida.org.br/ ojs/index.php/rede-unida/article/view/794.

16. Souza JBPG, Mendes LL, Binoti ML. Perfil do aleitamento materno e da alimentação complementar em crianças menores de dois anos atendidas em um centro de referência da cidade de juiz de fora - MG. Rev APS [internet]. 2016 [acesso em 2019 jan 20]; 19(1):67-76. Disponível em: https://periodicos.ufjf. br/index.php/aps/article/view/15580. 
17. Carvalho CA, Fonsêca PCA, Nobre LN, et al. Sociodemographic, perinatal and behavioral factors associated to types of milk consumed by children under in six months: birth coort. Cienc. Saúde Colet. 2017 [acesso em 2019 jan 20]; 22(11):3699-710.

18. Rocci E, Fernandes RAQ. Dificuldades no aleitamento materno e influência no desmame precoce. Rev Bras Enferm. 2014 [acesso em 2019 jan 20]; 67(1):22-7.

19. Boff ADG, Paniagua LM, Scherer S, et al. Mother's social / economic aspects and level of knowledge about breastfeeding Aspectos socioeconômicos e conhecimento de puérperas sobre o aleitamento materno. Audiol - Commun Res. 2015; 20(2):141-5.

20. Schincaglia RM, Oliveira AC, Sousa LM, et al. Práticas alimentares e fatores associados à introdução precoce da alimentação complementar entre crianças menores de seis meses na região noroeste de Goiânia. Epidemiol e Serviços Saúde. 2015; 24(3):465-74.

21. Monteiro FR, Buccini GS, Venâncio SI, et al. Influence of maternity leave on exclusive breastfeeding. J Pediatr [internet]. Sociedade Brasileira de Pediatria; 2017 [acesso em 2019 jan 20]; 93(5):475-81. Disponível em: http://dx.doi.org/10.1016/j.jpedp.2017.07.003.

22. Marcolin M, Marcolin CGDA, Souza AR, et al. Amamentação e os desafios enfrentados pela mulher trabalhadora: um relato de experiência. J Manag Prim Heal Care. 2016; 7(1):99-99.

23. Pereira BSA, Kluber TE, Zilly A, et al. O paradigma no direito de amamentar no Brasil The paradigm on the right to breastfeed in Brazil. Rev Interdiscip Estud em Saúde. 2017; 6(1):85-95.

24. Barbosa GEF, Silva BV, Pereira JM, et al. Initial breastfeeding difficulties and association with breast Dificuldades iniciais com a técnica da amamentação e fatores associados a problemas com a mama em puérperas. Rev Paul Pediatr. 2017; 35(3):265-72.
25. Capucho LB, Forechi L, Lima RDCD, et al. Fatores que interferem na amamentação exclusiva. Rev Bras Pesq Saúde. 2017; 19(1):108-13.

26. Algarves TR, Julião AMS, Costa HM. Aleitamento materno: influência de mitos e crenças no desmame precoce. Rev Saúde em foco [internet]. 2015 [acesso em 2019 jan 20]; 2(1):151-67. Disponível em: http:// www4.fsanet.com.br/revista/index.php/saudeemfoco/article/view/912.

27. Moraes BA, Gonçalves AC, Strada JKR, et al. Factors associated with the interruption of exclusive breastfeeding in infants up to 30 days old. Rev Gaúcha Enferm. 2016; 37(esp): e2016-0044.

28. Sousa ELO, Melo LGNS, Medeiros DMF. Práticas de complementação ao leite materno: concepções de puérperas sobre aleitamento materno e uso de fórmula infantil Breast-milk supplementation practices: conceptions of puerperal mothers about breastfeeding and. Rev Bras Educ e Saúde. 2019; 9(2):76-84.

29. Amaral LJX, Sales SS, Carvalho DPSRP, et al. Fatores que influenciam na interrupção do aleitamento materno exclusivo em nutrizes. Rev Gaúcha Enferm [internet]. 2015 [acesso em 2019 jan 20]; 36(esp):12734. Disponível em: https://www.scielo.br/pdf/rgenf/ v36nspe/en_0102-6933-rgenf-36-spe-0127.pdf.

30. Sabra A, Sabra Filho A, Corsini L, et al. Frequência e justificativa para o uso de fórmulas infantis, em maternidades, em substituição e junto ao leite materno. J food allergy [internet]. 2017; 6(4):115-8. Disponível em: https://journaloffoodallergy.com/journal/ JFA-V6-N4.pdf $\#$ page $=15$.

\footnotetext{
Recebido em 26/12/2019

Aprovado em 10/08/2020

Conflito de interesses: inexistente

Suporte financeiro: não houve
} 